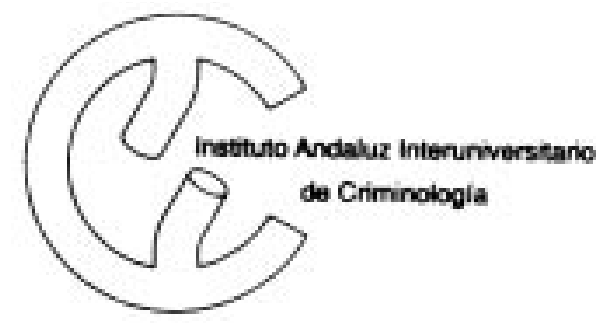

Director: Per Stangeland

Coordinadora: Ma José Garrido de los Santos Publicado por la Sección de Málaga del IAIC Facultad de Derecho, Universidad de Málaga Campus de Teatinos, 29071 MALAGA

Tel:(95) 2132325 - Fax:(95) 2132242

Depósitolegal:MA857/1996ISSN:1137-2427

Internet: Http://www.gen.com/emn/ crimi

El presente boletín es la reseña de una investigación más amplia sobre la victimización de mujeres inmigrantes marroquíes en Málaga, llevada a cabo durante 1997.

Los resultados fueron presentados en una comunicación en el $9^{\circ}$ Simposium internacional sobre Victimología celebrado en Amsterdam en agosto de 1997. El trabajo completo se publicará en el número de abril de la revista Cuadernos de Política Criminal.

\title{
Victimización de mujeres inmigrantes en Málaga
}

\section{Autoras: \\ Elisa García España \\ Auxiliadora Durán Durán \\ Anabel Cerezo Domínguez}

\section{INTRODUCCION}

Tradicionalmente la literatura victimológica reconoce la vulnerabilidad diferencial que muestran ciertos colectivos sociales ante el delito: mujeres, niños, ancianos, marginados, extranjeros, etc. En muchos casos, se da como explicación de este riesgo diferencial el estilo de vida de los sujetos, la conjunción de unas determinadas características, etc. Los resultados de encuestas de victimización, junto a las teorías del estilo de vida de la víctima y de la oportunidad, nos llevan a identificar al colectivo de inmigrantes como un grupo especialmente vulnerable a la victimización: desconocimiento en muchos casos de costumbres e idioma, necesidad de trabajar, etc. Es, además, un grupo social que difícilmente denunciará los hechos o acudirá a la policía para solicitar ayuda.

En España uno de los colectivos de inmigrantes que más ha crecido y que tiene un mayor nú- mero de integrantes es el de origen magrebí, especialmente las mujeres marroquíes. Esta inmigración hacia la península no se inició hasta los años setenta. En aquellos años se permitía la entrada al territorio español de estos ciudadanos extranjeros e incluso se fomentaba por su necesidad como mano de obra barata. En Málaga, el porcentaje de mujeres inscritas en el Consulado marroquí en 1990 fue de un 46,6\%, cifra que se sitúa por encima de la recogida en ciudades como Madrid o Barcelona. De ahí que se haya considerado a Málaga como pionera en la inmigración femenina marroquí en España.

Esto se explica por el gran auge turístico de la Costa del Sol, y su consolidación como asentamiento de personas con alto poder adquisitivo, las cuales demandaban mano de obra para el servicio doméstico. De los trabajadores regularizados, el $22 \%$ se concentra en el servicio doméstico. Concretando el perfil laboral de las mujeres regularizadas, el $60 \%$ de las mujeres trabajaban en el servicio doméstico y el $13 \%$ en cafeterías, restaurantes y hoteles. Ello lleva a la conclusión de que la mayoría de estas mujeres están en puestos de trabajo difíciles de controlar por la Administración, lo que podía facilitar condiciones laborales y salariales irregulares. En consecuencia, sus condiciones generales de vida propiciarían una mayor victimización.

\section{OBJETIVOS}

- Descripción de las condiciones de vida y problemas que padece este colectivo: situación laboral, vivienda, relaciones familiares, problemas de ajuste cultural, etc.

- Análisis de la posible victimización sufrida desde su llegada a España, y comparación del tipo de delitos padecidos con los datos existentes sobre mujeres malagueñas, obtenidos de una encuesta de victimización ya realizada por el I.A.I.C.

\section{HIPOTESIS}

1. Las condiciones de trabajo de la mayoría de las mujeres de la muestra serán precarias: bajos salarios, ausencia de contrato, horarios excesivos, etc.

2. Elevada incidencia de deli-

\section{Boletín \\ Criminológico \\ $\begin{array}{llll}N^{o} & 33 & \text { Marzo } & 1998\end{array}$ \\ Página




\section{Descripción de la muestra}

Se han realizado entrevistas anónimas y voluntarias a 32 mujeres marroquíes en dos asociaciones de ayuda a inmigrantes en Málaga.

La media de edad de la muestra fue de 37,9 años, con una desviación típica de 9,5 años.

La procedencia de estas mujeres se corresponde con las tradicionales zonas emisoras de emigración hacia la provincia de Málaga. Los inmigrantes asentados en esta provincia proceden mayoritariamente de Casablanca, y en segundo término de las provincias que comprenden la zona de Yebala (en la que se incluyen Chauen, Larache, Tetuan y Tánger). Esta misma distribución se recoge en la muestra, ya que el $37,5 \%$ viene de Casablanca y el 34,3\% de la zona de Yebala.

La motivación fundamental para venir a España ha sido de tipo económico $(56,3 \%)$ o por cuestiones familiares $(31,3 \%)$. En general, emigraron de modo independiente $(59,4 \%)$, no han tenido graves problemas con su familia tras su decisión $(68,8 \%)$ y llegaron a España como turistas $(53,1 \%)$.

Unicamente cuatro mujeres tenían contrato previo a su entrada.

La mitad de ellas están casadas, mientras que el resto están separadas/divorciadas o viudas $(43,8 \%)$. Tan sólo dos mujeres señalaron estar solteras.

La media de hijos es de 2, aunque la desviación típica resulta bastante elevada, 2,1 .

En cuanto al nivel de formación, el $81,3 \%$ es analfabeta o tiene unos estudios mínimos (suele ser habitual en este segundo caso que hayan asistido algún tiempo al colegio para aprender francés y árabe).

El objetivo de estas mujeres es, bien obtener la nacionalidad española $(53,1 \%)$, bien simplemente permanecer en España (31,3\%). Sólo una mujer manifestó de modo claro su idea de volver a Marruecos y otras dos su deseo de ir a otro país. El 68,1\% de los maridos muestra una actitud favorable ante el hecho de que su mujer trabaje. tos padecidos, al ser un colectivo que reúne diversas condiciones que favorecen esta incidencia: ser mujeres, extranjeras, no tener en muchos casos documentos legales, necesidad de trabajar, etc.

3. En cuanto al tipo de delitos sufrido, si bien los delitos de mayor incidencia serán aquéllos de carácter económico relacionados con su actividad laboral, la victimización será similar a la padecida por las mujeres españolas: tirones, agresiones sexuales, etc.

4. Elevada incidencia del delito de malos tratos, que no será reconocido como tal y estará justificado por sus tradiciones culturales.

\section{RESULTADOS}

\section{Llegadas}

Destaca el hecho de que la mujer marroquí toma, en muchas ocasiones, la iniciativa en el proceso migratorio, sobre todo en el primer momento: en la decisión de emigrar.

El caso típico con el que nos hemos encontrado es el de la mujer que, por motivos económicos, decide emigrar. Las necesidades económicas que provocan la salida de su país se producen frecuentemente tras una ruptura matrimonial -por muerte, separación o divorcio-, o por la precaria situación económica del propio matrimonio; la iniciativa de emigrar es de la propia mujer.

No faltan, por supuesto, aunque con menor frecuencia, las mujeres solteras que, bien por no encontrar trabajo en su país, bien por no conformarse con el trabajo que allí tenían, deciden buscar mejor suerte en otro lugar.

Como caso excepcional y único nos parece interesante destacar el caso de una mujer que llegó a España como estudiante a pesar de la oposición paterna.

Otro caso frecuente es que la mujer marroquí adopte un papel secundario en el primer momento del proceso migratorio, pues viene a España tras haber contraído matrimonio. Lo que sorprende es el número de casos en los que ese matrimonio se contrajo con un español con el que vino posteriormente.

Junto a estos supuestos, no faltan los casos de mujeres cuyos maridos emigraron años antes de contraer matrimonio y, una vez situados en España, volvieron a Marruecos para casarse e instalarse aquí.

Ninguna de las mujeres de la muestra entró de forma ilegal. La entrada como turista fue la forma mayoritarimente elegida, ya que casi todas ellas llegaron a España en una época anterior a la legislación que actualmente regula el acceso de los inmigrantes. Hemos de tener en cuenta que se trata de mujeres que llevan bastantes años aquí, por lo que la opción turista era la más cómoda y fácil.

\section{Problemas padecidos}

Entre los problemas iniciales destaca el del idioma $(68,8 \%$ señala haber tenido dificultades iniciales), pero la mayoría no tuvo excesivos problemas legales $(59,4 \%)$, raciales $(90,6 \%)$ o religiosos $(96,9 \%)$. Finalmente, si bien en general la vivienda no supuso un problema para la mayoría de estas mujeres, el $31,3 \%$ indica haber tenido dificultades en este aspecto.

También es interesante destacar que el 56\% de nuestra muestra se ha sentido sola o aíslada en España.

\section{Condiciones laborales}

De entre las mujeres que trabajan, el 50\% de las entrevistadas lo hacen en el servicio doméstico como interna, mientras que el $22,2 \%$ trabaja en empleos relacio-

\section{Boletín Criminológico $\begin{array}{lllll}N^{o} & 33 & \text { Marzo } & 1998 & \text { Página }\end{array}$ 2}


nados con la restauración o como canguro, y el 27,7\% desempeña otros trabajos. En relación a la existencia de contrato laboral, en la actualidad el $70,5 \%$ señala tener un contrato (12 mujeres de las 17 que afirman estar trabajando en el momento de la entrevista), el 46, $1 \%$ indica haberlo tenido siempre, el $30,7 \%$ nunca, y el $23 \%$ en ocasiones.

El salario medio de estas mujeres es de 49.312 pesetas, aunque puede existir una variación de 16.197 pesetas. De las mujeres de la muestra que trabajan, la gran mayoría disfruta de vacaciones $(80,9 \%)$, tiene un día o día y medio de descanso a la semana $(95,6 \%)$, no se siente discriminada $(86,9 \%)$, está satisfecha con sus condiciones laborales $(75 \%) \mathrm{y}$ las relaciones que mantienen con las personas con las que trabaja son buenas (90\%). El 61,9\% trabaja más de ocho horas.

Los casos más frecuentes incluyen la situación de mujeres que llegan a España y empiezan a trabajar generalmente en el sector de servicio doméstico (50\%) y en la mayoría de las ocasiones en la modalidad de internas. Si bien en ocasiones nos encontramos con casos de mujeres que se han dedicado desde su llegada a las labores del hogar $(21,9 \%)$.

\section{Trato de las instituciones}

Prácticamente todas las mujeres entrevistadas señalan que han recibido un buen trato por parte de las instituciones y también la información necesaria (únicamente el $6,3 \%$ se queja del trato recibido).

\section{Expectativas y opiniones sobre España}

La mayoría coincide en señalar que ya habían tenido trato con españoles antes de emigrar. Ade- más, no los categorizan como grupo homogéneo, sino que van a indicar que al igual que entre los propios marroquíes hay grandes diferencias entre personas. Con excepciones puntuales (quejas sobre falta de trabajo, racismo, burocracia, etc.), en general se muestra una opinión positiva y un cumplimiento en mayor o menor medida de sus expectativas de encontrar trabajo, mejorar su nivel de vida etc.

Muchas de las entrevistadas indican que no tenían una opinión especial de los españoles: «los hay buenos y malos como los marroquíes», aunque algunas creen que son más abiertos. Se da con frecuencia el tener amigos marroquíes y españoles. E incluso algunas mujeres prefieren mantener en mayor medida contactos con españoles.

\section{Victimización}

Las mujeres entrevistadas presentan un porcentaje de victimización del 37,5\% (índice de prevalencia), habiendo sufrido más de un delito alguna de ellas. Se han contabilizado 17 incidentes (índice de incidencia). Si comparamos el índice de prevalencia de la población objeto de estudio con el relativo tanto a la población femenina residente $(56 \%)$ como a los turistas que visitan la Costa del Sol $(11,9 \%)$, podemos afirmar que las mujeres marroquíes que residen en esta zona no presentan un alto riesgo de victimización. Se ha de tener en cuenta, que el porcentaje calculado para la población residente abarca únicamente los últimos doce meses, mientras que con respecto a los turistas refleja la victimización ocurrida durante su estancia en España, dos semanas por término medio. En nuestro estudio, las mujeres marroquíes fueron preguntadas por todos aque- llos delitos padecidos desde su llegada al país.

Esta baja tasa de victimización puede explicarse si atendemos al tipo de vida que llevan. Son mujeres que salen poco de casa, tienen pocos bienes materiales y no frecuentan lugares de diversión, en definitiva, no reúnen las características típicas de los grupos de riesgo. Los delitos de los que más frecuentemente son víctimas son los cometidos contra el patrimonio (hurto y robo, en su modalidad de "tirón"), delitos que, por otra parte, parecen sufrir más las mujeres residentes que los hombres, con lo que podemos afirmar que son delitos que afectan en su mayoría a la población femenina. La nacionalidad de los autores del delito es, en su mayoría, española (en el $58 \%$ de los casos las mujeres indicaron que el agresor era español). Suelen denunciarlos, sobre todo si el objeto material sustraído han sido documentos (58\%).

En cuanto a los casos de malos tratos conyugales, el porcentaje de mujeres de la muestra que afirmaron haber sufrido este tipo de delitos fue elevado $(6,8 \%)$ si lo comparamos con el número de mujeres que en nuestro país denuncian malos tratos conyugales anualmente (aproximadamente una media de 16.000); parece pues que este tipo de actos tiene lugar entre las inmigrantes con mayor frecuencia. No obstante, es necesario tener en cuenta que la cifra de denuncias presentadas por las mujeres residentes no muestra la incidencia real de casos de malos tratos habituales, estimándose que la cifra negra es muy elevada. Aún así, la incidencia de los malos tratos no ha sido tan elevada como se pudiera pensar en un primer momento. A pesar de proceder estas mujeres de un país con unas connotaciones culturales propensas a que esta práctica sea habi-

\section{Boletín Criminológico $\quad N^{o} 33 \quad$ Marzo $1998 \quad$ Página 3}


tual y justificada (debido a la discriminación que las mujeres sufren en todos los aspectos), de las entrevistas realizadas entresacamos una impresión diferente. Aunque pueden o no conceptualizar la práctica de malos tratos físicos habituales como un delito, al menos no lo justifican, sino todo lo contrario, lo consideran un hecho grave.

\section{CONCLUSIONES}

Tras esta visión genérica de las condiciones en las que viven las mujeres marroquíes en Málaga, pasamos a analizar las hipótesis específicas planteadas en el estudio.

1. Las condiciones de trabajo de la mayoría de las mujeres de la muestra serán precarias: bajos salarios, ausencia de contrato, horarios excesivos, etc.

La primera de nuestras hipótesis parece cumplirse en términos generales. El sueldo medio no supera las 50.000 pesetas mensuales para unas mujeres que suelen trabajar más de ocho horas. Sin embargo, el índice de contratación resulta más elevado del que podría esperarse en un principio. Así, las malas condiciones laborales no parecen muy diferentes de las que han venido manteniendo o puedan mantener algunas españolas en el mismo sector o en empleos similares. No obstante, hemos de tener en cuenta que han sido las marroquíes las que han acaparado una modalidad de servicio doméstico que ya no atrae a las mujeres españolas, pese a la crisis económica: el servicio doméstico interno. Durante los años 50 y 60, décadas de gran migración del campo a la ciudad, fue ésta una modalidad de trabajo típica para las chicas que provenían de los pueblos. Es evidente que este tipo de ocupación plantea menos problemas, e incluso puede presentar aspectos positivos (casa, comida, etc.), para personas que vienen de otra región o país y no tienen cargas familiares a las que atender diariamente. Pero también representa un estilo de vida que dificulta la integración social de estas mujeres fuera de su grupo de origen.

En el caso de la comunidad marroquí, no hemos observado que ese trabajo constituya una plataforma hacia otras ocupaciones mejor pagadas, y suelen mantenerse como internas desde su llegada. Se muestran satisfechas con sus condiciones de trabajo, ya que en Marruecos la situación laboral ofrece muchas menos oportunidades y también la calidad de vida para ellas y su familia sería menor.

2. Elevada incidencia de delitos padecidos, al ser un colectivo que reúne diversas condiciones que favorecen esta incidencia: ser mujeres, extranjeras, no tener en muchos casos documentos legales, necesidad de trabajar, etc.

3. En cuanto al tipo de delitos sufrido, si bien los delitos de mayor incidencia serán aquéllos de carácter económico relacionados con su actividad laboral, la victimización será similar a la padecida por las mujeres españolas: tirones, agresiones sexuales, etc.

Por su referencia al mismo ámbito de análisis: victimización, las hipótesis 2 y 3 serán comentadas de modo conjunto.

Dados los porcentajes de victimización obtenidos, parece claro que estas mujeres presentan unos índices menores que la población residente o que los turistas que visitan la zona. Aunque ello vaya en contra de la hipótesis formulada, son las mismas teorías que nos condujeron a desarrollarla las que nos ofrecen una alternativa de explicación ante estos resultados. Como mencionamos más arriba, la vida de las mujeres de nuestra muestra es bastante limitada: se reduce al trabajo y la familia si la tienen, apenas salen de casa más que para comprar o para visitar a alguna amiga, etc. En definitiva, se nos perfila un estilo de vida que ofrece pocas oportunidades para la victimización, a menos que ésta provenga del entorno más inmediato: abusos en el trabajo, malos tratos del marido, o se produzca durante la realización de actividades como la compra en el rastro, el paseo a los niños, etc. No obstante, los delitos más frecuentes (tirones y hurtos) se corresponden con los padecidos por la población femenina de Málaga. Finalmente, el bajo índice de victimización no creemos que se deba tanto a su integración social como a la ausencia de ésta.

4. Elevada incidencia del delito de malos tratos, que no será reconocido como tal y estará justificado por sus tradiciones culturales.

En este apartado, encontramos que el porcentaje de la muestra que indica haber sufrido malos tratos es bastante elevado, especialmente si tenemos en cuenta que no es una muestra seleccionada con la intención de encontrar un tasa elevada de este delito. No obstante, hay que destacar que se trata de incidentes más o menos aíslados en la actualidad, si bien una de estas mujeres sí había sufrido malos tratos reiterados por parte de su marido en Marruecos.

En general, la justificación ante estas conductas es menor de la que habíamos hipotetizado. En esta respuesta quizás influya el hecho de que se trata de mujeres que llevan bastantes años viviendo fuera de Marruecos. También podemos señalar que el porcentaje sería más elevado si hubiésemos incluído a aquellas mujeres que recibieron malos tratos familiares $(7,6 \%)$, esto es, aquéllos cometidos por cualquier miembro de su familia.

\section{Boletín \\ Criminológico \\ $N^{o} \quad 33 \quad$ Marzo 1998 \\ Página

